\title{
Physical activity of the university's senior students
}

Mikhail M. Kolokoltsev ${ }^{1 \mathrm{ABCDE}}$, Wladyslaw Jagiello ${ }^{2 \mathrm{ABCDE}}$

${ }^{1}$ Irkutsk National Research Technical University, Russia

${ }^{2}$ Gdansk University of Physical Education and Sport, Gdansk, Poland

Authors' Contribution: A - Study design; B - Data collection; C - Statistical analysis; D - Manuscript Preparation; E - Funds Collection.

\begin{abstract}
Purpose: $\quad$ To prevent hypodynamics, to evaluate the volume and level of weekly physical activity of the university's senior students.

Material: $\quad$ The study involved students $(n=244)$ aged $19-20$ years $(n=157$ - boys, $n=87$ - girls). The students studied in the 4th year of the Technical University (Russia). The following parameters were investigated: physical activity (PA), the intensity of metabolic processes and motor skills. The volume of weekly physical activity was determined by a short form of the IPAQ-SF physical activity questionnaire. The level of physical activity intensity was determined by the formula of a metabolic equivalent of task (MET) (min/week). According to MET, students are divided into three groups: 1st group with a high level; 2nd group with average level; 3rd group with low level. The battery of motor tests used to evaluate students' physical preparedness.

Results: $\quad$ The total intensive and non-intensive weekly motor activity of boys was 6.2 hours ( 372 min). This confirms with the standard volume ( 6 hours) recommended by WHO. The total motor activity of the girls (intense and non-intense) was 4.5 hours ( $271.6 \mathrm{~min}$ ) per week. More than a quarter of the surveyed boys had a high level of physical activity. About $62 \%$ of students had an average level and $12.7 \%$ had a low level. Among all surveyed girls $16.1 \%$ have a high level of physical activity, $41.4 \%$ had an average level and $42.5 \%$ had a low level. The results of boys with a low level of physical activity in all motor tests were lower than the results of boys with high and average levels of physical activity. The exception was the results of the Seated Forward Bend test $(p<0.05)$. In 6 motor tests, the results of girls with a low level of physical activity were worse than the results of female students with a high level of weekly physical activity $(p<0.05)$. There are no significant differences between the test results in girls with low and average levels of weekly physical activity.

Conclusions: After completing the course on the subject "Elective Courses in Physical Culture and Sports", the physical activity of students remains high enough. $12.7 \%$ of boys and $42.5 \%$ of girls with low levels of physical activity and MET were identified among the surveyed student population. This allows aligning them into a group at risk of developing non-communicable diseases. To reduce the hypodynamics of junior courses students at risk, it should use individually directed pedagogical technologies of physical education. In presenting the theoretical section of the subject "Physical Culture" to the senior courses students it is necessary to strengthen their motivation for independent motor activity.
\end{abstract}

Keywords: physical culture, physical activity, metabolic equivalent, physical preparedness.

\section{Introduction}

Physical activity is the body motor actions of a person with the help of muscle force, accompanied by a level of energy consumption higher than metabolism at rest [1]. Physical activity means the usual types of daily motor activity of the person.

According to some authors, hypodynamia is one of the reasons for ischemic heart disease, diabetes [2], obesity [3], cancer and other non-communicable diseases [4]. One of the reasons for the health deterioration of modern youth is the global tendency for hypodynamia and hypokinesia [5-7]. According to the documents of the World Health Organization (WHO), more than 1/3 of the world's population does not reach the required level of physical activity [8].

The decrease in the quality of students' health begins before their admission to a higher education institution [911]. Insufficient physical activity of schoolchildren leads to a violation of the adaptation mechanisms of the body and reduces the indicators of their physical development

(c) Mikhail M. Kolokoltsev, Wladyslaw Jagiello, 2020

doi:10.15561/20755279.2020.0104 and physical preparedness [12, 13]. However, children who exercise for at least $60 \mathrm{~min}$ per day have a high level of health [14].

Further education at the university is associated with an intensive learning process [15]. Changes in the students' quality of life occur as a result of an increase in the volume of neuropsychiatric factors in the educational environment and their impact on the adaptive potential of the organism [16-18]; ignoring the basics of healthy lifestyles against the hypodynamia background [19, 20]. Physical activity is an effective drug-free means of preserving and enhancing the reserve capacity of the human body [21-23]. Physical activity is a complex biosocial phenomenon [24]. There are reports in the literature on the study of motor activity of junior courses students of higher education institutions $[25,26]$. The study of the structure and gender features of the physical activity of senior students seems to be relevant. These students have a reduced volume of controlled physical activity. This is due to the completion of academic training courses on the subject "Elective courses in physical culture and sports". There is an increase in the number of students 
at the potential risk of developing the non-communicable diseases of hypodynamic genesis.

A person's physical activity is measured by three methods: time spent per day or week (timekeeping); energy costs (indirect calorimetry); the number of daily locomotions (pedometry) [27, 28]. The questionnaire for assessing the level of physical activity allows assessing the objective questionnaire for a person's weekly motor activity [International Questionnaire on Physical Activity, IPAQ-Short Form (IPAQ-SF)] [29]. This questionnaire is acceptable according to the validity and reproducibility [30], and it was tested in several regions of Russia [31] and in other countries [32].

Physical activity of university students in the Russian Federation is determined in the volume of 6-8 hours per week [33]. In the recommendations of various authors on the volume of activity of students' motor activity (measured by time spent), the standards differ significantly: from 7-14 hours per week [34] and up to 1618 hours per week [35]. To maintain the health of people aged 18-64, it is proposed the following: a minimum rate of weekly motor activity of 2 hours 30 minutes (not less than 30 minutes per day for 5 days a week) with the exercise of moderate aerobic orientation; or at least 1 hour 15 minutes ( 25 minutes for 3 days) with high-intensity loads [36, 37].

The analysis of modern literature indicates the tendency of student youth to hypodynamia and reduction of energy costs. Therefore, a comprehensive study of the issues of the physical activity of university students is relevant and appropriate.

The purpose of the study. To prevent hypodynamics, evaluate the volume and level of weekly physical activity of university students.

\section{Material and Methods.}

Participants.

Students $(\mathrm{n}=244)$ aged $19-20$ years $(\mathrm{n}=157$ - boys, $\mathrm{n}$ $=87-$ girls) participated in the study. The students studied in the $4^{\text {th }}$ year of the Technical University (Russia). All students completed the course on the subject "Elective Course in Physical Culture and Sports".

\section{Design of the study}

The volume of motor loads and the evaluation of the weekly physical activity level of students were determined by the short form of the IPAQ-SF physical activity questionnaire [28]. The metabolic equivalent of task (MET) was calculated [38] to determine the intensity of metabolic processes in the body of boys and girls. According to the IPAQ-SF questionnaire, the level of physical activity intensity of a person is determined by the formula of the metabolic equivalent of task (MET) calculation (Table 1).

The total weekly volume of human energy costs is determined by the sum of the metabolic equivalents of low, average and high levels of physical activity intensity:

$\mathrm{MET}_{\text {total }}=\mathrm{MET}_{\mathrm{h}}+\mathrm{MET}_{\mathrm{a}}+\mathrm{MET}_{1}(\mathrm{~min} /$ week$)$.

where,

$\mathrm{MET}_{\mathrm{h}}$ is a high level of physical activity intensity,

MET $_{\mathrm{a}}$ is an average level of physical activity intensity,

MET $_{1}$ is a low level of physical activity intensity.

According to MET, the students were divided into three groups:

$1^{\text {st }}$ group with a high level of physical activity intensity. These are students who have a week:

- 3 or more days of high-intensity PA with a metabolic cost of at least 1500 MET;

- or a daily load of any intensity with a metabolic cost of at least $3000 \mathrm{MET}$.

$2^{\text {nd }}$ group with an average level of physical activity intensity. These are students who have a week:

- 3 or more days of high physical activity, lasting at least $20 \mathrm{~min}$;

- at least 5 days of average physical activity intensity or walking, with a duration of at least 30 minutes;

- or at least 5 days of loads of any intensity with a metabolic cost of 600 MET.

$3^{\text {rd }}$ group with low intensity of physical activity. Students whose physical activity does not meet the abovementioned criteria are included.

The evaluation of physical preparedness of senior students was performed applying a battery of motor tests [39]:

- $\quad 5 \times 10 \mathrm{~m}$ shuttle test, sec.;

- $\quad 100 \mathrm{~m}$ run, sec;

- $\quad 1000$ m run, min, sec;

- Pull-Up Bars (boys), quantity of times;

- Cadence Push-Up Test, (girls), quantity of times;

- $\quad$ Eurofit Sit Up Test (for $30 \mathrm{sec}$ ), quantity of times;

- $\quad$ Seated Forward Bend, cm;

- $\quad$ Standing Long Jump Test (Broad Jump), cm;

Statistical analysis. The sample volume (n), mean value $(\mathrm{M})$, minimum, maximum, standard deviation $(\sigma)$, standard error $(\mathrm{m})$ were calculated applying the software "Microsoft Excel", "StatSoft Statistica 6.1". The reliability was determined by parametric methods [40].

Table 1. The method of determining the level of physical activity intensity by MET (min / week)

\begin{tabular}{ll}
\hline $\begin{array}{l}\text { Level of physical activity } \\
\text { intensity (min / week) }\end{array}$ & The formula for calculating MET min / week by the IPAQ \\
\hline High (h) & $8.0^{*} \times$ [duration of high intensity PA $\left.(\mathrm{min})\right] \times[$ number of days per week in \\
& which high intensity physical activity occurred] \\
Average (a) & $4.0^{*} \times$ [duration of moderate intensity PA $\left.(\mathrm{min})\right] \times[$ number of days per week] \\
Low (I) & $3.3^{*} \times$ [walking time $\left.(\min )\right] \times[$ number of days per week] \\
\hline
\end{tabular}

Note. * - the conversion coefficients for the corresponding PA intensity level 


\section{Results}

Table 2 presents the results of a study of weekly physical activity of senior students.

Table 2 is shown that the physical activity of boys is the significantly higher physical activity of girls $(\mathrm{p}<0.05)$. We did not find gender differences in the duration of daily walking and their weekly number ( $\mathrm{p}>0.05)$.

The figure illustrates the students' division by levels of the metabolic equivalent of task (MET) of weekly physical activity.

The $1^{\text {st }}$ group included 54 students (high MET level). Among them, there were $57.7 \%$ more boys than girls.

The $2^{\text {nd }}$ group included 133 students (average MET level). At the same time, there were $49.2 \%$ more boys than girls.

The $3^{\text {rd }}$ group (low MET level) included 57 students. It is $23.4 \%$ of the total number of students. There were 3.5 times fewer boys than girls. We suppose that students of this group are at high risk of developing non-communicable diseases and therefore require special attention from the physical education teachers and medical service of the university.

Among all surveyed boys, $25.5 \%$ have a high level of physical activity. $61.8 \%$ of students have an average level and $12.7 \%$ have a low level. Among all girls, $16.1 \%$ of female students have a high level, $41.4 \%$ have an average level and $42.5 \%$ have a low level. Thus, the quantitative ratio of boys with different levels of PA is expressed by the ratio: $2 \mathrm{~h}: 4.8 \mathrm{a}$ : 11 (conventional signs: $\mathrm{h}-$ high, $\mathrm{a}-$ average, $1-$ low). In girls, the ratio is represented as $1_{\mathrm{h}}$ $: 2.5_{\mathrm{a}}: 2.6_{1}$ (conventional signs: $\mathrm{h}$ - high, a - average, $1-$ low).

The energy costs of boys with high and average weekly physical activity were $34.6 \%$ and $38.7 \%$ higher (respectively) than the energy costs of girls (Table 3 ). The energy costs of boys and girls at walking are approximately equal.

The evaluation of the motor tests results of senior students with different levels of weekly physical activity are presented in tables 4 and 5 .

It was found that the results of all motor tests in boys with low levels of physical activity were worse than in boys with high and average levels of motor activity $(\mathrm{p}<0.05)$. The exceptions are the results of the Seated Forward Bend test. The significant differences between the results of boys with average and high levels of physical activity ( $p$ $<0.05$ ) were recorded in two strength tests ("Pull-Up Bars" and "Eurofit Sit Up Test (for $30 \mathrm{sec}$ )").

Table 2. Student questionnaire results by the IPAQ-SF questionnaire $(M \pm m)$

\begin{tabular}{|c|c|c|c|c|c|c|c|}
\hline \multirow[b]{3}{*}{ Questioned } & \multicolumn{7}{|c|}{ Question numbers on the IPAQ-SF } \\
\hline & 1 & 2 & 3 & 4 & 5 & 6 & 7 \\
\hline & $\begin{array}{l}\text { The } \\
\text { number of } \\
\text { days with } \\
\text { intensive* } \\
\text { physical } \\
\text { activity per } \\
\text { week }\end{array}$ & $\begin{array}{l}\text { Duration of } \\
\text { intensive } \\
* \text { physical } \\
\text { activity per } \\
\text { day } \\
\text { (min) }\end{array}$ & $\begin{array}{l}\text { The number } \\
\text { of days } \\
\text { of non- } \\
\text { intensive } \\
* * \text { physical } \\
\text { activity per } \\
\text { week }\end{array}$ & $\begin{array}{l}\text { Duration } \\
\text { of non- } \\
\text { intensive } \\
\text { physical } \\
\text { activity } \\
\text { per day } \\
\text { (min) }\end{array}$ & $\begin{array}{l}\text { How } \\
\text { many } \\
\text { days a } \\
\text { week } \\
\text { do you } \\
\text { walk? }\end{array}$ & $\begin{array}{l}\text { How } \\
\text { long do } \\
\text { you walk } \\
\text { per day? } \\
\text { (min) }\end{array}$ & $\begin{array}{l}\text { How many } \\
\text { hours a } \\
\text { day do } \\
\text { you spend } \\
\text { sitting or } \\
\text { lying down? } \\
\text { (hour) }\end{array}$ \\
\hline $\begin{array}{l}\text { Boys } \\
(n=157)\end{array}$ & $2.83 \pm 0.11$ & $52.26 \pm 1.6$ & $3.42 \pm 0.16$ & $65.6 \pm 2.7$ & $6.46 \pm 0.10$ & $71.9 \pm 2.4$ & $7.1 \pm 0.18$ \\
\hline Girls (n=78) & $2.42 \pm 0.17$ & $45.39 \pm 2.45$ & $3.08 \pm 0.24$ & $52.5 \pm 3.8$ & $6.39 \pm 0.15$ & $65.3 \pm 3.18$ & $8.2 \pm 0.29$ \\
\hline $\begin{array}{l}\text { reliability } \\
\text { (p) }\end{array}$ & $p<0.05$ & $p<0.05$ & $p>0.05$ & $\mathrm{p}<0.05$ & $p>0.05$ & $\mathrm{p}>0.05$ & $p<0.05$ \\
\hline
\end{tabular}

Note. * - intensive physical activity includes motor actions that lead to increased respiratory rate; heart rate increase by more than $20 \%$ and continue for at least $10 \mathrm{~min}$ at one time (swimming, running, shaping, hard physical work, etc.).

** - Non-intense physical activity includes motor actions that increase the breathing rate compared to the normal condition and continue for at least $10 \mathrm{~min}$ at one time (walking is not included).

Table 3. The energy costs of students for physical activity (MET min / week)

\begin{tabular}{llll}
\hline \multirow{2}{*}{ Gender } & \multicolumn{2}{l}{ Level of weekly physical activity intensity } \\
\cline { 2 - 4 } & High & Average & Low \\
\hline Boys & $1183.2 \pm 155.3$ & $897.4 \pm 48.6$ & $1532.8 \pm 189.6$ \\
Girls & $878.7 \pm 67.2$ & $646.8 \pm 56.8$ & $1376.9 \pm 167.5$ \\
Reliability $(p)$ & $p<0.05$ & $p<0.05$ & $p>0.05$ \\
\hline
\end{tabular}




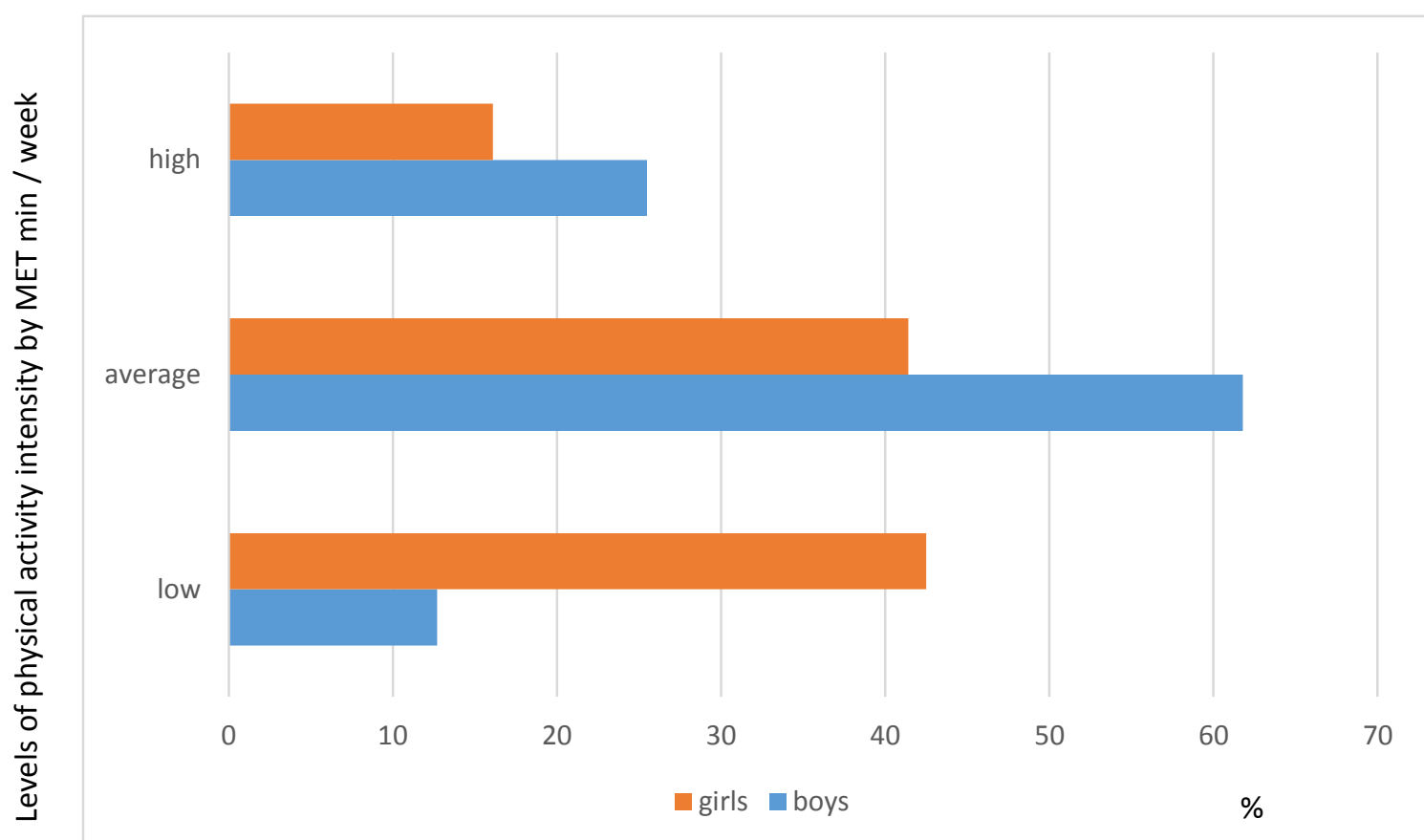

Fig. The students' division by levels of metabolic equivalent of task of weekly physical activity (\%).

Table 4. Results of boys motor tests $(M \pm m)$

\begin{tabular}{|c|c|c|c|c|}
\hline \multirow{2}{*}{ Motor tests } & \multicolumn{3}{|c|}{ Level of weekly physical activity intensity } & \multirow{2}{*}{$\mathbf{p}$} \\
\hline & High $(n=20)$ & Average $(n=97)$ & Low $(n=40)$ & \\
\hline $\begin{array}{l}5 \times 10 \text { m shuttle test, } \\
\text { sec.; }\end{array}$ & $18.6 \pm 0.06$ & $16.05 \pm 0.04$ & $16.01 \pm 0.02$ & $\begin{array}{l}p_{1}-p_{2}<0.05 ; p_{1}-p_{3}<0.05 ; \\
p_{2}-p_{3}>0.05\end{array}$ \\
\hline $100 \mathrm{~m}$ run, $\mathrm{m}, \mathrm{sec}$ & $14.9 \pm 0.42$ & $13.84 \pm 0.36$ & $13.67 \pm 0.33$ & $\begin{array}{l}p_{1}-p_{2}<0.05 ; p_{1}-p_{3}<0.05 \\
p_{2}-p_{3}>0.05\end{array}$ \\
\hline $1000 \mathrm{~m}, \mathrm{~min}, \mathrm{sec}$ & $3: 54.52 \pm 0: 00.6$ & $3: 52.84 \pm 0: 00.9$ & $3: 51.75 \pm 0: 00.8$ & $\begin{array}{l}p_{1}-p_{2}<0.05 ; p_{1}-p_{3}<0.05 ; \\
p_{2}-p_{3}>0.05\end{array}$ \\
\hline $\begin{array}{l}\text { Pull-Up Bars, quantity } \\
\text { of times; }\end{array}$ & $9.2 \pm 0.12$ & $11.2 \pm 0.16$ & $12.5 \pm 0.18$ & $\begin{array}{l}p_{1}-p_{2}<0.05 ; p_{1}-p_{3}<0.05 ; \\
p_{2}-p_{3}<0.05\end{array}$ \\
\hline $\begin{array}{l}\text { Eurofit Sit Up Test (for } \\
30 \text { sec.), quantity of } \\
\text { times; }\end{array}$ & $26.3 \pm 0.20$ & $29.8 \pm 0.22$ & $33.4 \pm 0.25$ & $\begin{array}{l}p_{1}-p_{2}<0.05 ; p_{1}-p_{3}<0.05 ; \\
p_{2}-p_{3}<0.05\end{array}$ \\
\hline $\begin{array}{l}\text { Seated Forward Bend, } \\
\mathrm{cm} \text {; }\end{array}$ & $16.9 \pm 0.28$ & $16.8 \pm 0.25$ & $16.7 \pm 0.23$ & $\begin{array}{l}\mathrm{p}_{1}-\mathrm{p}_{2}>0.05 ; \quad \mathrm{p}_{1}-\mathrm{p}_{3}>0.05 ; \\
\mathrm{p}_{2}-\mathrm{p}_{3}>0.05\end{array}$ \\
\hline $\begin{array}{l}\text { Standing Long Jump } \\
\text { Test (Broad Jump), cm; }\end{array}$ & $235.3 \pm 2.33$ & $237.5 \pm 2.55$ & $243.4 \pm 2.74$ & $\begin{array}{l}p_{1}-p_{2}>0.05 ; \quad p_{1}-p_{3}<0.05 ; \\
p_{2}-p_{3}>0.05\end{array}$ \\
\hline
\end{tabular}

The evaluation of the motor tests results in girls with different levels of weekly motor activity is presented in Table 5.

There are no significant differences between the results of all tests in girls with low and average levels of weekly physical activity $(\mathrm{p}>0.05)$. Girls with low levels of physical activity showed the worst results in 6 motor tests, compared to other female students $(p<0.05)$. In girls with high levels of physical activity, the results of motor tests (coordination abilities, the strength of the muscles of the upper limbs and abdominal muscles) were higher, compared with the results of girls with average level ( $p$
$<0.05)$.

\section{Discussion}

It was found that the number of days of intensive physical activity exercises in boys was $16.9 \%$ more per week than in girls $(\mathrm{p}<0.05$, Table 2$)$. In this case, all students spent daily less than 1 hour on intensive physical activity. The daily intense physical activity in boys was $15.1 \%$ longer than in girls $(p<0.05)$. The total intensive weekly physical activity of boys and girls was 2.46 and 1.83 hours, respectively. The indicators of weekly intensive physical activity of students are much higher 
Table 5. The results of girls' motor tests $(M \pm m)$

\begin{tabular}{|c|c|c|c|c|}
\hline \multirow{2}{*}{ Motor tests } & \multicolumn{3}{|c|}{ Level of weekly physical activity intensity } & \multirow{2}{*}{$\mathbf{p}$} \\
\hline & Low $(n=37)$ & Average $(n=36)$ & High $(n=12)$ & \\
\hline $\begin{array}{l}\text { 5x10 m shuttle test, } \\
\text { sec.; }\end{array}$ & $21.8 \pm 0.3$ & $21.7 \pm 0.2$ & $20.1 \pm 0.4$ & $\begin{array}{l}p_{1}-p_{2}>0.05 ; p_{1}-p_{3}<0.05 \\
p_{2}-p_{3}<0.05\end{array}$ \\
\hline $100 \mathrm{~m}, \mathrm{sec}$ & $17.62 \pm 0.2$ & $17.69 \pm 0.6$ & $16.3 \pm 0.6$ & $\begin{array}{l}p_{1}-p_{2}>0.05 ; \quad p_{1}-p_{3}<0.05 \\
p_{2}-p_{3}>0.05\end{array}$ \\
\hline $1000 \mathrm{~m}, \mathrm{~min}, \mathrm{sec}$ & $5: 55 \pm 0: 0.7$ & $5: 53 \pm 0: 0.5$ & $5: 52 \pm 0: 0.9$ & $\begin{array}{l}p_{1}-p_{2}>0.05 ; \quad p_{1}-p_{3}<0.05 ; \\
p_{2}-p_{3}>0.05\end{array}$ \\
\hline $\begin{array}{l}\text { Cadence Push-Up Test, } \\
\text { quantity of times; }\end{array}$ & $37.9 \pm 0.26$ & $38.5 \pm 0.25$ & $47.8 \pm 0.55$ & $\begin{array}{l}p_{1}-p_{2}>0.05 ; p_{1}-p_{3}<0.05 ; \\
p_{2}-p_{3}<0.05\end{array}$ \\
\hline $\begin{array}{l}\text { Eurofit Sit Up Test (for } \\
30 \mathrm{sec} \text {.), quantity of } \\
\text { times; }\end{array}$ & $21.5 \pm 0.17$ & $21.8 \pm 0.19$ & $28.7 \pm 0.33$ & $\begin{array}{l}p_{1}-p_{2}>0.05 ; p_{1}-p_{3}<0.05 \\
p_{2}-p_{3}<0.05\end{array}$ \\
\hline $\begin{array}{l}\text { Seated Forward Bend, } \\
\mathrm{cm} \text {; }\end{array}$ & $15.9 \pm 0.16$ & $15.8 \pm 0.15$ & $15.6 \pm 0.77$ & $\begin{array}{l}p_{1}-p_{2}>0.05 ; p_{1}-p_{3}>0.05 ; \\
p_{2}-p_{3}>0.05\end{array}$ \\
\hline $\begin{array}{l}\text { Standing Long Jump } \\
\text { Test (Broad Jump), cm; }\end{array}$ & $168.8 \pm 2.1$ & $169.2 \pm 2.2$ & $176.8 \pm 3.3$ & $\begin{array}{l}\mathrm{p}_{1}-\mathrm{p}_{2}>0.05 ; \mathrm{p}_{1}-\mathrm{p}_{3}<0.05 ; \\
\mathrm{p}_{2}-\mathrm{p}_{3}>0.05\end{array}$ \\
\hline
\end{tabular}

in comparison with the results of students from another region of Russia (Surgut) with daily physical activity of 63 min per week [24]; in Swedish youths with daily physical activity of $23 \mathrm{~min}$ [41].

In boys, the number of training days per week with non-intensive physical activity increased by $9.9 \%$ than in girls ( $p>0.05)$. Daily non-intense physical activity of boys was $19.9 \%$ higher than that in girls. Weekly non-intense physical activity was 3.73 hours in boys and 2.69 hours in girls $(p<0.05)$. The results of our data do not differ from the indicators of the weekly volume of non-intensive physical activity of students in Surgut, Russia [24].

The total intensive and non-intensive weekly motor activity in boys was 6.2 hours ( $372 \mathrm{~min}$ ). This corresponds to the standard volume (6 hours) of performing weekly motor activity [33] and WHO recommendation [36]. The total motor activity of female students (intensive and nonintensive) was 4.5 hours (271.6 min per week), which is corresponded to WHO recommendation, but lower than recommended in Russia [33].

The total weekly physical activity (intensive + nonintensive + walking) in boys was $836.5 \pm 9.2 \mathrm{~min}$, in girls almost in $150 \mathrm{~min}$ less $-688.8 \pm 11.2 \mathrm{~min}(\mathrm{p}<0.05)$.

The low-mobility behavior of a person is accompanied by low energy costs. For example, time of inactivity (except time for sleep). These factors are confirmed in several studies [42, 43]. The time of daily and weekly inactivity in the surveyed boys was $13.4 \%$ and in $15.4 \%$, respectively, less than in girls $(\mathrm{p}<0.05)$.

One of the factors that significantly increase the risk of adult mortality is working at a computer monitor for more than 4 hours a day [44-46]. The survey results show that most students use a computer for more than 5 hours a day. This may indicate a potential risk for the formation of somatic non-communicable diseases in hypodynamic conditions.

Many authors paid attention to the study of the sedentary lifestyle of some countries as a factor of influencing human health [47-50]. This type of human behavior is characterized by low motor activity with a metabolic equivalent of task (MET) equal to $1-1.5 \mathrm{~min} /$ week (where 1 MET corresponds to rest) [51]. The average physical activity (150 min per week) reduces the risk of heart disease, stroke, type 2 diabetes, and other non-communicable diseases. Physical activity of a person exceeding 150 min per week is the most effective for maintaining and promoting health $[1,2]$.

The obtained results regarding the majority number of students with an average level of PA are confirmed with the data obtained by other authors [25, 52].

The students' division by physical activity levels, considering the values of MET, allows identifying students with hypodynamia and to carry out purposeful work among them to increase motivation to motor activity.

Conducted pedagogical research shows that the physical activity of boys is higher than girls. Gender differences in physical activity have been noted by researchers in Russia [24] and foreign countries [41, 53-55]. Analysis of the results of our studies showed that the daily and weekly total physical activity of boys is significantly higher than in girls. This is explained by girls sitting upright for a long period (Table 2). The survey showed that the number of boys involved in sports is more than girls.

Students respond positively to the importance of physical activity in the daily activities of youth. More than $30 \%$ of students regularly take part in sports groups, $24 \%$ do morning exercises, $22 \%$ do skiing, $36 \%$ cycle, $18 \%$ attend fitness clubs. The results of our research indicate a high physical activity of senior students after completion of training in the program of physical education at the university. The result of increasing students' motivation to motor activity is the purposeful work of the pedagogical staff of the Physical Education Department. This 
contributes to the development of students' research competence to carry out practical projects of sports competitions, festivals, and olympiads. Authors from Altai University (Russia) [56], Grodno (Belarus) [57], China [58, 59], Romania and Spain [60-62] report an increase in students' interest in physical education in the last 10 years.

The evaluation of the tests' results of the physical preparedness of the senior students indicates that motor skills are most developed in students with high levels of weekly physical activity. There are reports in the literature on the mutual influence of the volume of motor activity of students, their level of physical preparedness $[63,64]$ and the body mass index [65-68].

The screening study showed that using the IPAQSF questionnaire allowed determining the volume and intensity of weekly physical activity and the time of inactivity in senior students. The obtained results can be used in the theoretical training of senior courses students to correct their independent physical activity.

\section{Conclusions}

After completing the course on the subject "Elective Courses in Physical Culture and Sports", the physical activity of the university's senior students continues to be quite high.

The intensive and non-intensive weekly motor activity is following the WHO recommendation for the optimal level of motor activity in senior courses students at the technical university. In this case, the boys' total weekly intensive and non-intense physical activity is more than in girls. Among the surveyed population, $23,4 \%$ of students have low levels of physical activity, MET, motor skills. It is a marker of the risk of developing non-communicable diseases of the body.

Teachers of the Physical Education Department in junior courses should divide students into groups according to MET with one risk group for the development of non-communicable diseases; use innovative methods to increase students' motivation for the self-motor activity.

We suppose that further study of the features of the range of physical activity of students is a promising direction in the prevention of hypodynamia and healthpromoting future specialists.

\section{Conf ict of interest}

The authors declare no conflict of interest.

\section{References}

1. Global Strategy on Diet, Physical Activity and Health. [Internet]. WHO, 2004. [updated 2019 Jun 15; cited 2019 Nov 5]. Available from: https://www.who.int/dietphysicalactivity/ strategy/eb11344/strategy english_web.pdf

2. Global health risks: mortality and burden of disease attributable to selected major risks. [Internet]. WHO, 2009. Geneva, World Health Organization. [updated 2019 Jun 25; cited 2019 Nov 5]. Available from: https://apps.who.int/iris/ handle/10665/44203

3. Caballero BA. Nutrition Paradox - Underweight and Obesity in Developing Countries. The New England Journal of Medicine, 2005; 352(15): 1514- 1516. https://doi.org/10.1056/NEJMp048310

4. The global burden of disease: 2004 update. [Internet]. WHO, Geneva: 2008. [updated 2019 Jun 25; cited 2019 Nov 5]. Available from: http://slideplayer.com/slide/9840395

5. Basset D, Fitzhugh E, Heaz G, Erwin P, Frederick G, Wolff D. et al. Estimated energy expenditures for school-based policies and active living. American Journal of Preventive Medicine, 2013; 44(2): 108-113 https://doi.org/10.1016/j.amepre.2012.10.017

6. Olafsdottir AS, Torfadottir JE, Arngrimsson SA. Health Behavior and Metabolic Risk Factors Associated with Normal Weight Obesity in Adolescents. PLoS ONE, 2016;11 (8). https://doi.org/10.1371/journal.pone.0161451

7. Gerber M, Ludyga S, Mucke M, Colledge F, Brand S, Puhse U. Low vigorous physical activity is associated with increased adrenocortical reactivity to psychosocial stress in students with high stress perceptions. Psychoneuroendocrinology. https://doi.org/10.1016/j.psyneuen.2017.03.004

8. World Health Organization. European Regional Office. Physical Activity Strategy for the WHO European Region, 2016-2025. World Health Organization. European Regional Office. [Internet]. 2016. [updated 2019 Jun 25; cited 2019 Nov 5]. Available from: https://apps.who.int/iris/ handle $/ 10665 / 329416$

9. Krasnobon SV. Motor activity as a criterion of health level. Physical culture. Sport. Tourism. Motor Recreation, 2017; 2 (1): 46-52. (In Russian)

10.Khrushchev SV, Schleifer AA. Health Improvement of Children (Modern Problems): Chronicle. Journal of Sports Medicine of Russia, 2012; 1: 65. (In Russian)

11.Palomino-Devia C, Reyes-Oyola FA, Sanchez-Oliver A. Levels of physical activity, health-related quality of life, physical self-concept and body-mass index among Colombian students. Biomedica. 2018;38(2):224-231. https://doi.org/10.7705/biomedica.v38i0.3964

12.Sukharev AG. The concept of strengthening the health of children and adolescents in Russia. Healthy children of Russia in the XXI century. Moscow: Russia; 2009. (In Russian)

13.Kim TK. State of health and motor activity of children and young people as a social and pedagogical problem. Science and school, 2012;3:13-16. (In Russian)

14.Janssen I. Physical activity guidelines for children and youth. Applied Physiology Nutrition and Metabolism, 2007; 32:109- 121. https://doi.org/10.1139/H07-109

15.Gorelov AA, Tretiakov AA. Nervous-emotional tension and methods to increase students 'resilience to its effects. Belhorod, Russia: CPI "Politicra," 2012. (In Russian)

16.Abdullina LB. Formation of healthy lifestyle of students in conditions of modern university: practical-oriented aspect. Health saving education, 2014; 2: 78-82. (In Russian)

17.Sierra-Diaz MJ, Gonzalez-Villora S, Pastor-Vicedo JC, Lopez-Sanchez GF. Can We Motivate Students to Practice Physical Activities and Sports Through Models-Based Practice? A Systematic Review and Meta-Analysis of Psychosocial Factors Related to Physical Education. Frontiers in Psychology. 2019;10 https://doi.org/10.3389/fpsyg.2019.02115

18.DiBattistaR, Robazza C, RuizMC, BertolloM, VitaliF, Bortoli 
L. Student intention to engage in leisure-time physical activity: The interplay of task-involving climate, competence need satisfaction and psychobiosocial states in physical education. European Physical Education Review. 2019;25(3):761-777. https://doi.org/10.1177/1356336X18770665

19.Moy B, Renshaw I, Davids K. The impact of nonlinear pedagogy on physical education teacher education students' intrinsic motivation. Physical Education and Sport Pedagogy, 2016; 21 (5): 517-538. https://doi.org/10.1080/17408989.2015.1072506

20.Pengpid S, Peltzer K. Sedentary Behaviour, Physical Activity and Life Satisfaction, Happiness and Perceived Health Status in University Students from 24 Countries. International Journal of Environmental Research and Public Health. 2019;16(12). https://doi.org/10.3390/ijerph16122084

21.Munir Talović, Ifet Mahmutović, Eldin Jelešković, Denis Sedić, Haris Alić, Rasim Lakota, Šemso Ormanović, Nedim Čović, Emir Mustafović. Quantitative changes of specific motor abilities of students under the influence of regular and additional activitiesin sport and physical education. Port Science International scientific journal of kinesiology, 2015; 8 (2): $34-37$

22.Kozlov AV, Pasko GV, Khromina S I. (Eds). Optimal motor regime as a mandatory factor of healthy lifestyle of students. Sports, sports and educational and patriotic activities in universities: innovations in solving topical problems: IV International Scientific and Practical Conference. Tyumen, Russia: TIU, 2018. (In Russian)

23.Bergier J, Tsos A, Popovych D, Bergier B, Niznikowska E, Acs P, et al. Level of and Factors Determining Physical Activity in Students in Ukraine and the Visegrad Countries. International Journal of Environmental Research and Public Health. 2018;15(8). https://doi.org/10.3390/ijerph15081738

24.Loginov SI, Nikolayev AJ, Vetoshnikov AJ, Sagadeeva SG. Physical activity of students of two universities of Surgut according to the international questionnaire IPAQ. Theory and Practice of Physical Culture, 2015; 9:83-85. (In Russian)

25.Maximichina EV, Ugovskaya OV. To the question of the state of health and motor activity of students of junior courses. International Scientific Journal Symbol of Science, 2016; 122: 218-220. (In Russian)

26.Kondakov VL, Kopeikina EN, Usatov AN, Voronin IU, Balysheva NV. Comparative analysis of the magnitude and nature of motor activity of university students. Contemporary Science and Education Problems, 2015; 2-2. Available from: $\mathrm{http}: / /$ science-education.ru/ru/article/view?id=21811.

(In Russian)

27.Kobyakov YuP. Concept of human motor activity norms. Theory and Practice of Physical Culture, 2003; 11:20-23. (In Russian)

28.Kolpakova EM. Motor activity and its effect on human health. Health, Physical Culture and Sports. 2018; 1(8): 94-109. Available from: http://journal.asu.ru/zosh/article/ view/3818. (In Russian)

29.Cora L Craid, Alison L Marshall, Michael Sjostrom et all. International Physical Activity Questionnaire: 12-Country Reliability and Validity. Medicine Science in Sports Exercise. 2003:1381- 1395. https://doi.org/10.1249/01.MSS.0000078924.61453.FB

30.EUROHIS: Development of common tools for health surveys. Moscow, Russia: Human Rights, 2005. (In Russian)

31.Potemkina RA. Increasing physical activity in the population of Russia: current approaches to elaborating population programs. Preventive medicine, 2014; 1: 6-11. (In Russian)
32.Fiona C Bull, Tahlia S Maslin and Timothy Armstrong. Global Physical Activity Questionnaire (GPAQ): Nine Country Reliability and Validity Study. Journal of Physical Activity and Health, 2009; 6:790- 804. https://doi.org/10.1123/jpah.6.6.790

33. Strategy of development of physical culture and sports of Russia. Approved by Order of the Government of the Russian Federation No. 1101-r of 7 August 2009. (In Russian)

34.Matveev LP. About common problems of theory and practice of physical culture. Theory and practice of physics. Culture, 1982; 7: 5 - 8. (In Russian)

35.Nazarov of PA. Forecast of some time spent by student youth by 2000. Theory and practice of physics. cultures, 1977; 11: 59 - 62. (In Russian)

36.WHO Library cataloguing-in-publication data. Global recommendations on physical activity for health. Geneva, 2010.

37.Billinger SA, Arena R, Bernhardt J, Eng JJ, Franklin BA, et al. Physical activity and exercise recommendations for stroke survivors: a statement for healthcare professionals from the American Heart Association American Stroke Association. Stroke, 2014; 45 (8): 2532-2553. https://doi.org/10.1161/STR.0000000000000022

38. Guidelines for data processing and analysis of the international physical activity questionnaire (IPAQ) - short and long forms. [Internet]. 2005 November [updated 2019 Jun 15; cited 2019 Nov 5]. Available from: http://www. academia.edu/5346814/Guidelines_for_Data_Processing and_Analysis_of_the_International_Physical_Activity_ Questionnaire_IPAQ_Short_and_Long_Forms_Contents, free. - Title of screen. pdf

39.The president's challenge: Physical fitness test. [Internet]. 2011 July 14. [updated 2019 Jun 15; cited 2019 Nov 5]. Available from: https://www.neoshosd.org/site/handlers/ filedownload.ashx? moduleinstanceid $=5912 \&$ dataid $=1087 \&$ FileName $=$ Presidential\%20Fitness\%20booklet.pdf

40.Grzybovsky AM. Data types, distribution checking and descriptive statistics. Ecology of the person. 2008; 1: 52-58. (In Russian)

41.Hagstromer M, Ainsworth BE, Pekka O, Sjostrom M. Comparison of a Subjective and an Objective Measure of Physical Activity in a Population Sample. Journal of Physical Activity and Health. 2010;7: 541- 550. https://doi.org/10.1123/jpah.7.4.541

42.Ghrouz AK, Noohu MM, Manzar MD, Spence DW, BaHammam AS, Pandi-Perumal SR. Physical activity and sleep quality in relation to mental health among college students. Sleep and Breathing. 2019;23(2):627-634. https://doi.org/10.1007/s11325-019-01780-z

43.Sersar I, Mekhancha DE, Vuillemin A, Schneider SM, Nezzal L, Dahel-Mekhancha CC. Association of physical activity and sleep with the body composition of algerian university students. Science \& Sports. 2019;34(2):73-81. https://doi.org/10.1016/j.scispo.2018.09.002

44.Stamatakis E, Hamer M, Dunstan DW. Screen based entertainment time, all-cause mortality and hospital events follow-up. $J$. of the Amer. college of cardiology. 2011;57(3) : 292-299. https://doi.org/10.1016/j.jacc.2010.05.065

45.Adewale L Oyeyemi, Adetoyeje Y Oyeyemi, Babatunde O Adegoke, Fatima O Oyetoke, Habeeb N Aliyu, Salamatu $\mathrm{U}$ Aliyu, and Adamu A Rufai. The short international physical activity questionnaire: cross-cultural adaptation, validation and reliability of the Hausa language version in Nigeria. BMC Med Res Methodol. 2011; 11: 156. 
https://doi.org/10.1186/1471-2288-11-156

46.Penglee N, Christiana RW, Battista RA, Rosenberg E. Smartphone Use and Physical Activity among College Students in Health Science-Related Majors in the United States and Thailand. International Journal of Environmental Research and Public Health. 2019;16(8). https://doi.org/10.3390/ijerph16081315

47.Interdepartmental strategy for the formation of a healthy lifestyle, prevention and control of noncommunicable diseases for the period up to 2025. Moscow; 2016. (In Russian)

48. Townsend N, Wickramasinghe K, Williams J. Physical activity statistics 2015. London: Brit. Heart Foundation, 2015.

49.Gutierrez-Martinez L, Martinez RG, Gonzalez SA, Bolivar MA, Estupinan OV, Sarmiento OL. Effects of a strategy for the promotion of physical activity in students from Bogota. Revista De Saude Publica. 2018;52. https://doi.org/10.11606/S1518-8787.2018052017173

50.Snedden TR, Scerpella J, Kliethermes SA, Norman RS, Blyholder L, Sanfilippo J, et al. Sport and Physical Activity Level Impacts Health-Related Quality of Life Among Collegiate Students. American Journal of Health Promotion. 2019;33(5):675-682. https://doi.org/10.1177/0890117118817715

51.Pate RR, O'Neill JR, Lobelo F. The evolving definition of "sedentary". Exercise and sport sciences rev. 2008; $36 \quad$ (4):173- 178. https://doi.org/10.1097/JES.0b013e3181877d1a

52.Soto-Ruiz MN, Aguinaga-Ontoso I, Guillen-Grima F, Marin-Fernandez B. Changes in the physical activity of university students during the first three years of university. Nutricion Hospitalaria. 2019;36(5):1157-1162. https://doi.org/10.20960/nh.02564

53.Moral-Garcia JE, Ruiz-Ariza A, Grao-Cruces A, De La Torre-Cruz MJ, Martinez-Lopez EJ. Satisfaction of spanish high school students with physical education: gender, age, physical activity level and body type. South African Journal for Research in Sport Physical Education and Recreation. 2018;40(1):71-84.

54. Blanco H, Benavides EV, Tristan JL, Mayorga-Vega D. Physical activity body image and personal self-concept in female mexican university students. Revista De Psicologia Del Deporte. 2017;26:25-33.

55.Ledezma YSR, Vega DM, Perez JEP, Lujan JCB. Physical activity, physical self-concept and psychological well-being in women meajcan university students. Revista De Psicologia Del Deporte. 2017;26:61-69.

56.Denisova GS. The dependence of the body mass of students of a special department of the Altai State University on the nature of nutrition and the optimal level of motor activity. Health, Physical Culture and Sports, 2019;1(12):127-152. Available from: http://journal.asu.ru/index.php/zosh. (in Russian)

57.Spakov AI, Krumina LP, Mischenko AN, Obelevsky AG, Pavlyuti OV. Self-assessment of students "motor activity and their attitude to the organization of physical education (comparison of research data in 2005 and 2015). Healthsaving technologies and systems: psycho-pedagogical and medical-biological aspects. II International Scientific and
Practical Conference. Baranovici, Belarus. 2016. P.100-106. (In Russian)

58.Zhang Z, Chen B, Chen W. The mediating effect of perceived health on the relationship between physical activity and subjective well-being in Chinese college students. Journal of American College Health, 2019:1-8. https://doi.org/10.1080/07448481.2019.1645676

59.Xu F, Wang XR, Xiang DD, Wang ZY, Ye Q, Ware RS. Awareness of knowledge and practice regarding physical activity: A population based prospective, observational study among students in Nanjing, China. Plos One. 2017;12(6). https://doi.org/10.1371/journal.pone.0179518

60.Zurita-Ortega F, Badicu G, Chacon-Cuberos R, CastroSanchez M. Motivational Climate and Physical Activity: A Multigroup Analysis in Romanian and Spanish University Students. International Journal of Environmental Research and Public Health. 2019;16(11). https://doi.org/10.3390/ijerph16112013

61.Potop V, Timnea OC, Stanescu M. Improving sports technique of stretched Gienger salto on uneven bars based on biomechanical indicators. Modern Journal of Language Teaching Methods, 2017;7(8):472- 480. https://doi.org/10.2991/icmmse-17.2017.64

62.Potop V, Timnea O, Stănescu M. Correlative analysis of the kinematic and dynamic characteristics of sports technique used in acrobatic elements and performances achieved by junior gymnasts in balance beam events. Conference proceedings, Volume 17. Informatics, Geoinformatics and Remote Sensing, 2017;21: P. 231-238. https://doi.org/10.5593/sgem2017/21

63.Kubieva SS, Botagariev TA, Zhetimekov ET. Physical fitness and physical development of varios profiles university students. Health, Physical Culture and Sports, 2018; 2 (9): 26-49. Available from: http://journal.asu.ru/index.php/zosh. (in Russian)

64.Minibayeva ED, Vasilieva AG. Development of a methodology for determining and evaluating the formation of the level of motor activity of a student of a technical university. Scientific review. Pedagogical sciences. 2015; 2: 158-158.

65.McDonough DJ, Pope ZC, Zeng N, Lee JE, Gao Z. Comparison of College Student's Energy Expenditure, Physical Activity, and Enjoyment during Exergaming and Traditional Exercise. Journal of Clinical Medicine. 2018;7(11). https://doi.org/10.3390/jcm 7110433

66.Jagiełło W. Perkal's method of natural indicators in the assessment of internal proportions of body composition in persons practicing combat sports - a review. Archives of Budo, 2019; 15: 187-193.

67.Jagiello W. Differentiation of the body composition in taekwondo-ITF competitors of the men's Polish national team and direct based athletes. Archives of Budo, 2015;11:329338.

68.Elizabeth G Eakin, Kerry Mummery, Marina M Reeves, Sheleigh P Lawler, Grant Schofield, Alison J Marshall and Wendy J Brown Correlates of pedometer use: results from a community-based physical activity intervention trial (10,000 Steps Rockhampton). International Journal of Behavioral Nutrition and Physical Activity, 2007; 4(31):1- 7. https://doi.org/10.1186/1479-5868-4-31 


\section{Information about the authors:}

Mikhail M. Kolokoltsev; (Corresponding author); Doctor of Medical Sciences, prof.; http://orcid.org/0000-0001-6620-6296; mihm49@mail.ru; Irkutsk National Research Technical University; Irkutsk, Russia.

Wladyslaw Jagiello; http://orcid.org/0000-0001-7417-4749; wjagiello1@wp.pl; Department Combat Sports and Personal Training, Gdansk University of Physical Education and Sport; Kazimierza Górskiego 1, 80-336 Gdańsk, Poland.

\section{Cite this article as:}

Mikhail M. Kolokoltsev, Wladyslaw Jagiello. Physical activity of the university's senior students. Physical education of students, 2020;24(1):31-39.

https://doi.org/10.15561/20755279.2020.0104

This is an Open Access article distributed under the terms of the Creative Commons Attribution License, which permits unrestricted use, distribution, and reproduction in any medium, provided the original work is properly cited http://creativecommons.org/licenses/by/4.0/deed.en

Received: 02.12.2019

Accepted: 09.01.2020; Published: 04.02.2020 